\title{
The epidemiology and population-based incidence of influenza in two communities, Bandung District, West Java, Indonesia, 2008-2011
}

Dwi Agustian ( $\sim$ dwi.agustian@unpad.ac.id)

Faculty of Medicine Universitas Padjadjaran https://orcid.org/0000-0002-6122-0758

\section{Kuswandewi Mutyara}

Dept. of Public Health, Faculty of Medicine, Universitas Padjadjaran

Chrysanti Murad

Dept. of Basic Medical Sciences, Faculty of Medicine, Universitas Padjadjaran

Timothy M. Uyeki

National Center for Immunization and Respiratory Diseases, Centers for Disease Control and Prevention, Atlanta, Georgia

\section{Cissy B. Kartasasmita}

Dept. of Child Health, Faculty of Medicine, Universitas Padjadjaran

\section{Eric A.F. Simoes}

Center for Global Health, Colorado School of Public Health, University of Colorado School of Medicine, Aurora, Colorado

\section{Research article}

Keywords: epidemiology, incidence, influenza, Indonesia, pandemic, virus

Posted Date: August 29th, 2019

DOI: https://doi.org/10.21203/rs.2.13626/v1

License: @ (1) This work is licensed under a Creative Commons Attribution 4.0 International License. Read Full License 


\section{Abstract}

Background: Influenza surveillance is important for monitoring influenza virus circulation and disease burden to inform influenza prevention and control measures. The objective of this study was to describe the epidemiology and estimate the incidence of influenza in two small communities in West Java, Indonesia, before and after the 2009 H1N1 pandemic. Methods: A population-based surveillance study in the community health care setting was conducted to estimate the annual incidence of influenza. Real-time reverse transcription polymerase chain reaction assay was used for influenza case ascertainment. Results: The mean annual incidence of influenza A and B, adjusted for health care utilization, was $1.6(95 \% \mathrm{Cl} 1.3-2.0)$ and 0.7 (95\% Cl: 0.5-1.0) per 1,000 persons, respectively, with the most affected group being young and school-age children. Conclusions: Young and school-age children populations are potential targets for influenza vaccination in Indonesia.

\section{Background}

Seasonal influenza has been reported to have a disproportionate impact upon morbidity and mortality in developing countries. One study estimated that 90 million new cases of acute lower respiratory tract infections and 28,000-111,500 deaths were attributable to seasonal influenza in children younger than 5 years old in 2008 , with $99 \%$ of these deaths occurring in developing countries. ${ }^{1}$ Another study estimated that $291,243-645,832$ seasonal influenza-associated respiratory deaths occur annually worldwide. ${ }^{2}$ In addition, Southeast Asia was found to have the second highest estimated seasonal influenza associated mortality rate (3.5-9.2 deaths per 100,000 individuals), after Sub-Saharan Africa. ${ }^{2}$ These estimates suggest that influenza is an important public health problem in lower- and middle-income countries, including Indonesia.

Implementation of influenza prevention and control programs in Indonesia has been hindered by many factors, including the sparsity of data to guide policy makers. ${ }^{3}$ Although influenza vaccination of priority groups has been recommended in all countries by the WHO, the Indonesian government has not added influenza vaccination to the national immunization program. Baseline disease burden data are needed to assess the potential impact of influenza vaccination programs and other preventive measures. In Indonesia, information currently available on the morbidity and burden of influenza is from six surveillance studies ${ }^{4-9}$ conducted during 1999 to 2016 . These studies were mainly hospital-based and/or did not utilize a population-based approach. A recent population-based study of influenza morbidity in Indonesia focused on severe hospitalized influenza cases. ${ }^{7}$ Hospital-based studies underestimate the population incidence of the spectrum of disease and often capture patients from different areas, leading to difficulty in defining the population at risk. It is estimated that mild cases of uncomplicated influenza, of which most are not medically attended or lead to hospitalization, contribute to $98.7 \%$ of all estimated influenza-associated illness, ${ }^{10}$ potentially leading to economic losses due to absenteeism at schools and workplaces. Thus, there is a need for population-based studies in Indonesia to estimate influenza disease burden in the community that also take into account health care utilization.

To our knowledge, none of the previous studies in Indonesia estimated the burden of influenza outside the hospital setting within a welldefined community area or among a population at risk. The objective of this study was to describe the epidemiology of influenza by estimating the population-based incidence of influenza in two small, well-defined communities before, during, and after the $2009 \mathrm{H} 1 \mathrm{~N} 1$ pandemic. The study aimed to measure the total and age-specific morbidity of influenza in the community while addressing health care utilization.

\section{Methods}

\subsection{Study location and period}

This study was conducted in two peri-urban areas of Bandung District, West Java, Indonesia (Figure 1). The sites were selected as a part of the Zoonotic Avian Influenza-Human Animal Interface Project, following reports of human infections with highly pathogenic avian influenza A (H5N1) virus with severe lower respiratory tract disease from these sites who were managed at Dr. Hasan Sadikin General Hospital, Bandung in 2008. The study areas are located on a river basin surrounded by volcanic mountains with cooler temperatures (annual average of $23.6^{\circ} \mathrm{C} / 74.5^{\circ} \mathrm{F}$ ) compared to other Indonesian cities, at an elevation of $768 \mathrm{~m}$ above sea level. This region has a tropical climate with annual average rainfall ranging from 1,000-3,500 mm. In 2009, the total population in the two subdistricts was 163,024 , with a total area of approximately $21 \mathrm{~km}^{2}$. The age distribution in this population is comparable with Indonesia in general, with $69 \%$ of the population aged between 16-65 years. Bandung District has a reported life expectancy of 69.4 years (2010), ${ }^{11}$ similar to the national life expectancy (70 years), ${ }^{12}$ but slightly higher than the average for West Java (66.6 years). ${ }^{11}$ Stunting in children aged $<5$ years is $25 \%(2011),{ }^{11}$ higher than the national average of $19 \% .{ }^{12}$ There are three government-funded community public health centers (puskesmas) serving the area-in 
addition to private clinics - with a medical doctor to population ratio of approximately 1 to $25,000 .^{11}$ Puskesmas provide subsidized health care services, mostly for low-income patients. During the study period, the recent Indonesian national health insurance policy had not been implemented; so most healthcare expenditures were paid out of pocket. ${ }^{12}$ There are no published national data on influenza vaccination uptake or in these communities, but it is assumed that less than $1 \%$ of the population are vaccinated for influenza annually. ${ }^{13}$

\subsection{Data collection and quality control}

Surveillance for influenza was conducted among persons with influenza-like illness (ILI) from October 2008 to September 2011 at three puskesmas: two in Cileunyi Subdistrict and one in Soreang Subdistrict. Dedicated, trained study physicians were assigned to screen and enroll patients with signs and symptoms of ILI. ILI was defined as having a fever (measured temperature of $>37.5^{\circ} \mathrm{C}$ ) or history of fever or feverishness and antipyretic treatment and having either cough or sore throat. Only subjects residing within the study area, as proven by ID card, and willing to provide written informed consent were eligible for this study. Basic demographic and clinical information from all subjects were recorded using standardized pre-tested case report form. Nasal and oropharyngeal swabs were collected from all subjects with ILI and transported to Dr. Hasan Sadikin General Hospital Laboratory for influenza virus testing. Trained nurses conducted home visits at 2 weeks post enrollment, collecting information using a standardized pre-tested questionnaire on clinical outcomes, household, environmental risk factors, and house geo-coordinates which were recorded by a handheld GPS receiver. For seasonality analysis, secondary data on weather parameters (rainfall, relative humidity, maximum and minimum temperature) were collected during the study period from Bandung city BMKG (Indonesian Geophysics, Climatology, and Meteorology Agency), agency responsible for weather and climate monitoring in Indonesia.

To measure the size of the population at risk or study denominator, we conducted a census of the population within the administrative areas served by the three puskesmas. Four hundred forty-eight trained, local community health workers (kaders) used standard census forms to obtain basic household demographic data, including household size and age group of all household members, which was classified into five categories: (a) < 5 years old, (b) 5-15 years old, (c) 16-50 years old, (d) 50-65 years old, and (e) >65 years old. A field coordinator performed quality control audits and identified errors or missing values in the survey forms. Incomplete forms were returned to the kaders for verification and corrections. After the population lists and addresses were validated, trained field surveyors conducted door-to-door visits to verify addresses and recorded all house geo-coordinates using handheld GPS receivers. All of the data-cleaned forms were entered into a secured web-based system by a dedicated data entry operator.

\subsection{Statistical analysis}

The seasonality of influenza was illustrated through a time series graph, defining cases by virus type, influenza A subtype, and age group, overlaid by weather data (rainfall, relative humidity, maximum and minimum temperature) throughout the study period (Figure 2). Age group susceptibility was shown through a time series graph to show the age distribution of influenza positive cases by virus type and influenza $A$ subtype throughout the study period (Figure 3). Population-based cumulative incidences of symptomatic influenza A and B virus infections were estimated for 2009, 2010, 2011, and stratified by age. Adjustments were made for age group specific variation in Community Health Care Utilization (CHCU) and for direct standardization to census data. For our CHCU adjustment, data on percentage of the population with ILI seeking medical treatment at a community health center for each age group was from an unpublished study by Dwi Agustian et al. This multiplier was applied to calculate the adjusted age group specific number of cases (adjusted numerator). The age group categories used followed the classification as defined in census data. The adjusted numerator was calculated by dividing the number of cases for each age group by $\mathrm{CHCU}$ percentages and standardized for 1,000 persons. For all calculations of annual incidences, the same number of population at risk (denominator) for each age group, enumerated by the census, was used with the fixed/closed cohort population assumption during the study. The confidence intervals were calculated using the WHO method. ${ }^{14}$

\subsection{Laboratory methods}

Combined throat and nasal swabs from each subject were transported at $4-8^{\circ} \mathrm{C}$ in a Virus Transport Medium (Beckton-Dickinson, NJ, USA) to the Research Laboratory in Dr. Hasan Sadikin General Hospital. A one-step multiplex real-time RT-PCR assay was used for influenza A and $B$ viral RNA detection, using primer and probes in two separate assays by standard protocols. The first assay was comprised of specific primers and probes for matrix (M1) gene (Influenza A) and host glyceraldehyde-3-phosphte dehydrogenase (GADPH) gene (Influenza B). The second assay was comprised of primers and probes specifically for the $\mathrm{H} 1, \mathrm{H} 3$, and $\mathrm{H} 5$ hemagglutinin (HA) gene regions for influenza $A$ virus subtype detection. The probes were labeled with three fluorescent dyes (FAM, HEX, and Cy5, with emission wavelengths at 518, 556, and $667 \mathrm{~nm}$, respectively). Positive specimens for influenza A were further subtyped for H1N1pdm09, H3, and H5 using the CDC protocol. Positive specimens for influenza B were further characterized as Yamagata-like and Victoria-like viruses by RT-PCR using the WHO protocol. 


\section{Results}

From October 2008 to September 2011, study physicians identified and enrolled 3,305 ILI patients (Table 1). Overall, 456 (14\%) patients tested positive for influenza viruses, including $10.9 \%(359 / 3,305)$ influenza A and $2.9 \%(97 / 3,305)$ influenza B. Further subtyping for influenza A yielded 9 (2.5\%) H1N1, 157 (43.7\%) H1N1 pdm09, 193 (53.8\%) H3N2, and none for H5N1 virus. The majority of ILI patients were less than 15 years old with high school education or less. We found relatively higher than expected frequency of sneezing reported among influenza positive subjects $(25 \%-45 \%)$. Only six out of $3,305 \mathrm{ILI}$ subjects were hospitalized, of which only one person had laboratoryconfirmed influenza [influenza A(H3N2)] and none died.

Figure 2 illustrates the pattern of seasonality and circulation of different types/subtypes of influenza viruses. Five peaks of greater than $15 \%$ influenza positive occurred, with influenza activity identified every month except between December 2009 to February 2010. This window of zero detectable influenza activity occurred just after the first wave of the 2009 H1N1 pandemic. Through early 2009, seasonal influenza $A(H 1 N 1)$ virus was identified in our study population and later replaced in 2010 by influenza $A(H 1 N 1) p d m 09$ virus. Each peak of higher influenza virus activity was predominantly driven by a particular influenza A subtype or influenza B.

In Figure 3, influenza activity is shown by type, influenza A virus subtype, and age group, by 6-month intervals. In the first 6-month interval, there were relatively more $A(H 3 N 2)$ virus infections occurring in younger age groups; while in the second interval, adults aged 51-65 years had the highest percentage of ILI subjects with $\mathrm{A}(\mathrm{H} 3 \mathrm{~N} 2)$ virus infections. However, during the last interval, the percentage of $\mathrm{A}(\mathrm{H} 3 \mathrm{~N} 2)$ virus in the 51-65 years old group decreased, while increasing again in the younger age groups. In the second interval, $\mathrm{A}(\mathrm{H} 1 \mathrm{~N} 1) \mathrm{pdm} 09$ virus infections emerged, occurring more in the school age group (5-15 years old); while during the two last intervals of study (October 2010-March 2011 and April-September 2011), older adults were more impacted. B Yamagata-like virus had a higher infection percentage in school-age children in the first study interval, with elderly more impacted during the second interval.

During the study period, the estimated annual cumulative incidence of symptomatic influenza A virus infections varied from 1.6 to 2.3 per 1,000 persons and the annual cumulative incidence of symptomatic influenza B virus infections ranged from 0.1 to 0.7 per 1,000 persons, after adjusting for community health care utilization percentages. Children aged $<5$ years were most affected, with estimated annual incidence of 6.3 to 10.6 and 0.4 to 4.3 per 1000 persons for symptomatic influenza A and B virus infections, respectively. Persons aged $>65$ years had the lowest estimated annual incidence for both influenza A and B (Figure 4). The number of influenza cases adjusted by community health care utilization for ILI and population size (adjusted numerator) is presented in Table 2 . The estimated adjusted annual cumulative incidence of ILI, influenza A, and influenza B by age group is presented in Table 3.

\section{Discussion}

The seasonality of influenza we documented in West Java, Indonesia during 2008-2011 showed a typical pattern for a tropical region-with year-round influenza virus circulation, sharp short-spikes, and large variation of peak timing-and is consistent with previous studies by Beckett et al between $1999-2003^{5}$ and Kosasih et al during 2003-2007. ${ }^{9}$ Peaks in influenza incidence coincided with higher precipitation months which generally occurred between December to March, except for July-August 2009 when A(H1N1)pdm09 virus emerged. Periods of high influenza activity ranged from 2 to 6 months, followed by low influenza activity for 2 to 4 months. Every year, we observed two or three peaks of increased influenza activity, with each peak typically predominated by a different virus and variability in the age group with the highest proportion of influenza positives from season to season. This variation could be due to differences in immune susceptibility by age, introduction of bias from differential health seeking behavior by age group or seasonal changes in health care seeking behavior, or chance variation due to smaller sample size when stratified by season and age group. However, a previous community cohort study in Vietnam also reported differences in impacted age groups by year. ${ }^{15}$

This continuous and dynamic year-round circulation of influenza viruses in West Java suggests that the best timing of influenza vaccination is not easily defined; therefore, if a national influenza vaccination program is implemented in Indonesia, one strategy is for influenza vaccination to begin as soon as influenza vaccine is available each year. One study suggested that influenza vaccination should be given before the Hajj, ${ }^{16}$ since thousands of people travel from Indonesia to the Hajj annually and influenza vaccination is required for Hajj pilgrims at entry into Saudi Arabia. However, the dates of the Hajj pilgrimage vary from year to year, adding practical challenges to this implementation. Alternatively, since increases in influenza activity coincide with high precipitation months, influenza vaccination could be implemented before the start of the rainy season, usually around October or November.

We observed that following the introduction of the 2009 H1N1 pandemic virus in Indonesia, overall influenza virus activity in the population dropped significantly and was not detectable in our study during January 2010. This was despite the relatively higher precipitation levels during that interval (Figure 2). Other studies conducted during the same period, including a study in East Java, Indonesia by Yamaoka et al ${ }^{4}$, 
in rural Thailand by Baggett et $\mathrm{al}^{17}$, in an urban Kenya by Katz et $\mathrm{al}^{18}$, and in Ha Nam District, Vietnam by Horby et al ${ }^{15}$, also showed a similar pattern of low seasonal influenza A and B virus activity after the first 2009 H1N1 pandemic wave. This suggests that the first wave of the pandemic might have led to a disruption of influenza virus activity afterward; not only in Indonesia, but also in other tropical climate countries. We also observed displacement of seasonal influenza $A(\mathrm{H} 1 \mathrm{~N} 1)$ virus by the emergence of influenza $A(\mathrm{H} 1 \mathrm{~N} 1)$ pdm09 virus in mid2009.

To our knowledge, there are no data on the population-based incidence of uncomplicated influenza in Indonesia. The estimated annual incidence of influenza $A$ in the community varied from 1.6 to 2.3 per 1,000 persons during the 3 years of our study. The $\mathrm{CHCU}$ rates we used to adjust the incidence were comparable with the estimated medically-attended rate among cases of influenza from a study in South Africa. ${ }^{10}$ The incidence of influenza in our study was low compared to the influenza incidence based among ambulatory patients in subtropical China (4.1 to 19.2 per 1,000 population in 2008 and 2009), ${ }^{19}$ Kenya (13.6 to 23 per 1,000 person-years in 2007 to 2010 ), ${ }^{18}$ and Bangladesh (130 to 170 per 1,000 person-years in 2009 and 2010). ${ }^{20}$ The lower influenza incidence in our study might reflect differences in the study populations (health seeking behavior, demographics, nutrition, and medical risk factors) and health system factors (health care accessibility), ${ }^{3}$ or study design and methodology (inclusion criteria, case definition, laboratory testing, and estimation approach).

We found children younger than 5 years old to be the most affected age group for both influenza A-and B-associated illness, with estimated incidence of 7 to 10.6 per 1,000 person-years and 0.4 to 4.3 per 1,000 person-years, respectively. The exception was during 2010 , when school-age children (6-15 years old) had the highest estimated annual incidence of influenza B. Other studies in Indonesia and Kenya reported that the highest incidence of hospitalized influenza-associated severe acute respiratory infection was in children under 5 years old. ${ }^{7,21}$ Our finding based upon virologic testing that showed young children were most affected by influenza is consistent with a community cohort study that utilized serological testing for influenza virus detection. ${ }^{22}$ School-age children had the second highest influenza incidence, similar to what was reported in a community cohort study in Vietnam. ${ }^{15}$ One study indicated that children aged 5-17 years are a driver of influenza A virus epidemics and that influenza vaccination of this group may contribute to reducing the overall impact upon the community. ${ }^{23}$

This study showed a trend of decreasing annual cumulative incidence with increasing age for both influenza A and B cases (Figure 4). The age-specific influenza incidence trends did not change when we performed stratified analyses by influenza A virus subtype, influenza B, or study sites. Persons older than 65 years old had very low estimated influenza incidence compared to younger age groups (Table 2),

consistent with the findings of an influenza surveillance study conducted during a similar period in East Java, Indonesia. ${ }^{4}$ The small number of older adult subjects enrolled in this study, which appeared to be proportional with the Indonesian population age structure, implied a higher uncertainty or random error margin. It is possible that the small number of infections we detected in older adults was because elderly persons may not always seek medical care or may not manifest fever with influenza when presenting for primary care and would have been missed by our ILI case definition, so we would have underestimated influenza disease burden in the elderly population. To perform sensitivity analysis, we also calculated the annual incidence among elderly by using a lower CHCU percentage among elderly (21.7\%) as reported from another Indonesian study, ${ }^{24}$ but the incidence of influenza among elderly was still the lowest among all age groups (Supplementary Table 1 ).

There were several limitations of this study. It is known that most persons with influenza do not seek medical care ${ }^{10,21}$ and estimates of disease burden in the community, based on passive surveillance case detection, need to account for health care utilization and other factors such as subject refusal. ${ }^{25}$ We adjusted our incidence estimates to account for health care utilization of persons with ILI to account for this bias. However, the health care utilization percentage used for adjustment in this study was derived from an unpublished survey that was conducted after our study (2014) with limited sample size. In 2014, the National Health Security program (JKN) for Indonesian universal health care was launched that increased health care utilization in general, including for persons with ILI. The three clinics that participated in ILI surveillance were open 5 days per week and it is possible that some persons with ILI were missed if the clinics were open 7 days per week. Therefore, our adjusted incidence estimates likely underestimate the incidence of ILI and influenza in the community. Moreover, health care utilization is dependent on access to medical services, which may vary by location, while we assumed the same level for the whole study area. Therefore, the adjustments made in this study might not fully address health seeking behavior that differs temporally and geographically. In addition, the confidence intervals of the incidence estimates were calculated by the WHO method, which does not address uncertainty in the proportion of ILI cases that present to included clinics, and could lead to further imprecision of the incidence estimates. We also did not assess asymptomatic influenza virus infections, and since enrollment and testing for influenza required meeting the ILI case definition, symptomatic individuals with influenza virus infection without ILI and who sought medical care were not captured. Therefore, our estimates of symptomatic influenza incidence underestimate the overall burden of influenza in the community. The refusal rate was very low, but we did not record the number and the characteristics of the refusal group and were unable to adjust for the percentage of persons who decline to participate in the study; we assumed refusals occurred similarly across age groups. To estimate the population at risk, we 
assumed a fixed cohort population, which may have changed over the study period. Overall, the study population in these two areas was relatively small and might limit the generalizability of findings to other areas of Indonesia.

\section{Conclusions}

The mean annual incidence of influenza A and B, adjusted for health care utilization, was 1.6 (95\% Cl 1.3-2.0) and 0.7 (95\% Cl: 0.5-1.0) per 1,000 persons, respectively, with the most affected group being young and school-age children in West Java, Indonesia. Therefore, these populations are potential targets for influenza vaccination. This study reiterates the importance of pediatric populations in lower- and middle-income countries as a target for influenza vaccination and other prevention measures.

\section{List Of Abbreviations}

WHO: World Health Organization

ILI: Influenza-like illness

GPS: Global Positioning Service

BMKG: Badan Meteorologi, Klimatologi, dan Geofisika

CHCU: Community Health Care Utilization

RT-PCR: Reverse transcription polymerase chain reaction

RNA: Ribonucleic Acid

\section{Declarations}

\section{Ethics approval and consent to participate}

Participation was voluntary with all subjects giving written informed consent. For those participants under 16 years old, the written informed consent was obtained from the parent or guardian. All data were kept confidential and analysis was performed on de-identified data. The study was approved by the Colorado Multiple Institutional Review Board and the Ethical Committee of Faculty of Medicine, Universitas Padjadjaran, by ethical clearance number 50/UN6.C1.3.2/KEPK/PN/2016.

\section{Consent for Publication}

Not Applicable

\section{Availability of data and materials}

The datasets used and/or analysed during the current study are available from the corresponding author on reasonable request.

\section{Competing interests}

The authors declare that they have no competing interests

\section{Funding}

This study data collection and analysis was funded by the National Center for Immunization and Respiratory Diseases, Centers for Disease Control and Prevention (CDC), Atlanta, Georgia, USA. The manuscript writing of this study was supported by USAID through Sustainable Higher Education Research Alliances (SHERA) Program, Center for Collaborative Research on Acute Respiratory Infections (CCR-ARI) contract no. IIE00000078-UNPAD-01 under prime award no AID-497-A-16-00004.

\section{Authors' contributions}

DA, CB, ES designed the study. DA, KM collected the data. CM conducted laboratory work. DA, KM analysed the data. DA wrote the manuscript. TU, ES review and edit the manuscript. All authors read and approved the final manuscript. 
We thank The CIRAI field team (Putri Tessa, Panji Dewa, Agus Kurniawan, lip, Cahyana, and Toto) for assistance in collecting and entering the data; The database team (Tri Mulyani, Gilang Tandika) for maintaining the CIRAl web-based database system, Bandung District Health Office, and FKUP-RSHS laboratory team (Nur Izzatun Nafsi, Yeni Rendiani) for performing real-time RT-PCR assay for influenza viruses. We also thank Rowena Crow for editing assistance, and Fikrianti Surachman and Ginanjar Syuhada who helped format the manuscript for submission. This study was funded by the National Center for Immunization and Respiratory Diseases, Centers for Disease Control and Prevention (CDC), Atlanta, Georgia, USA and partially supported by USAID through Sustainable Higher Education Research Alliances (SHERA) Program, Center for Collaborative Research on Acute Respiratory Infections (CCR-ARI) contract no. IIE00000078-UNPAD-01 under prime award no AID-497-A-16-00004.

\section{References}

1. Nair H, Brooks WA, Katz M, et al. Global burden of respiratory infections due to seasonal influenza in young children: a systematic review and meta-analysis. Lancet. 2011;378(9807):1917-1930. doi:10.1016/S0140-6736(11)61051-9

2. Iuliano $\mathrm{AD}$, Roguski KM, Chang $\mathrm{HH}$, et al. Estimates of global seasonal influenza-associated respiratory mortality: a modelling study. Lancet. 2018;391(10127):1285-1300. doi:10.1016/S0140-6736(17)33293-2

3. Lee VJ, Ho ZJM, et al. Advances in measuring influenza burden of disease. Influenza Other Respi Viruses. 2018;12(1):3-9. doi:10.1111/irv.12533

4. Yamaoka M, Palilingan JF, et al. Virological surveillance of human influenza in Indonesia, October 2008-March 2010. Microbiol Immunol. 2011;55(7):514-517. doi:10.1111/j.1348-0421.2011.00344.x

5. Beckett CG, Kosasih H, Ma'roef C, et al. Influenza surveillance in Indonesia: 1999-2003. Clin Infect Dis. 2004;39(4):443-449. doi:10.1086/422314

6. Storms AD, Kusriastuti R, et al. The East Jakarta Project: surveillance for highly pathogenic avian influenza A(H5N1) and seasonal influenza viruses in patients seeking care for respiratory disease, Jakarta, Indonesia, October 2011-September 2012. Epidemiol Infect. 2015;143(16):3394-3404. doi:10.1017/S0950268815000771

7. Susilarini NK, Haryanto E, Praptiningsih CY, et al. Estimated incidence of influenza-associated severe acute respiratory infections in Indonesia, 2013-2016. Influenza Other Respi Viruses. 2018;12(1):81-87. doi:10.1111/irv.12496

8. Rudge J, Budayanti NS, et al. Surveillance and characterisation of influenza among patients with influenza-like illness in Bali, Indonesia. Int J Infect Dis. 2012. doi:10.1016/j.ijid.2012.05.038

9. Kosasih H, Roselinda, et al. Surveillance of Influenza in Indonesia, 2003-2007. Influ Other Respi Viruses. 2012. doi:10.1111/j.17502659.2012.00403.x

10. McAnerney JM, Gottberg A von, Cohen AL, et al. Quantifying how Different Clinical Presentations, Levels of Severity and Healthcare Attendance Shape the Burden of Influenza-Associated Illness: a Modeling Study from South Africa. Clin Infect Dis. 2018. doi:10.1093/cid/ciy1017

11. Dinas Kesehatan KB. Laporan Tahunan 2015. Pemerintah Kabupaten Bandung. https://www.bandungkab.go.id/uploads/Laptah 2015_Website.pdf. Published 2015. Accessed May 5, 2019.

12. WHO Regional Office for South-East Asia. The Republic of Indonesia Health System Review.; 2017.

13. Hirve S. Seasonal Influenza Vaccine Use in Low and Middle Income Countries in the Tropics and Subtropics A systematic review. World Heal Organ Publ Data. 2015.

14. World Health Organisation (WHO). A manual for estimating disease burden associated with seasonal influenza. World Health Organization. https://apps.who.int/iris/bitstream/handle/10665/178801/9789241549301_eng.pdf?sequence=1. Published 2015. Accessed May 16, 2019.

15. Horby P, Mai le Q, et al. The epidemiology of interpandemic and pandemic influenza in Vietnam, 2007-2010: the Ha Nam household cohort study I. Am J Epidemiol. 2012;175(10):1062-1074. doi:10.1093/aje/kws121

16. Saha S, Chadha M, et al. Influenza seasonality and vaccination timing in tropical and subtropical areas of southern and south-eastern Asia. Bull World Health Organ. 2014. doi:10.2471/BLT.13.124412

17. Baggett HC, Chittaganpitch $\mathrm{M}$, et al. Incidence and Epidemiology of Hospitalized Influenza Cases in Rural Thailand during the Influenza A (H1N1)pdm09 Pandemic, 2009-2010. Goldstein E, ed. PLoS One. 2012;7(11):e48609. doi:10.1371/journal.pone.0048609

18. Katz MA, Lebo E, et al. Epidemiology, seasonality, and burden of influenza and influenza-like illness in Urban and Rural Kenya, 20072010. J Infect Dis. 2012. doi:10.1093/infdis/jis530

19. Guo R ning, Zheng $\mathrm{H}$ zhen, et al. Epidemiologic and economic burden of influenza in the outpatient setting: A prospective study in a subtropical area of China. PLoS One. 2012. doi:10.1371/journal.pone.0041403

Page $7 / 13$ 
20. Azziz-Baumgartner E, Alamgir A, et al. Incidence of influenza-like illness and severe acute respiratory infection during three influenza seasons in Bangladesh, 2008-2010. Bull World Health Organ. 2012. doi:10.2471/BLT.11.090209

21. Dawa JA, Chaves SS, et al. National burden of hospitalized and non-hospitalized influenza-associated severe acute respiratory illness in Kenya, 2012-2014. Influenza Other Respi Viruses. 2018. doi:10.1111/irv.12488

22. Hayward AC, Fragaszy EB, et al. Comparative community burden and severity of seasonal and pandemic influenza: Results of the Flu Watch cohort study. Lancet Respir Med. 2014. doi:10.1016/S2213-2600(14)70034-7

23. Worby CJ, Chaves SS, et al. On the relative role of different age groups in influenza epidemics. Epidemics. 2015;13:10-16. doi:10.1016/j.epidem.2015.04.003

24. Praptiningsih CY, Lafond KE, et al. Healthcare-seeking behaviors for acute respiratory illness in two communities of Java, Indonesia: a cross-sectional survey. J Epidemiol Glob Health. 2016;6(2):77-86. doi:10.1016/j.jegh.2016.01.002

25. Murray J, Cohen A, et al. Determining the Provincial and National Burden of Influenza-Associated Severe Acute Respiratory IIIness in South Africa Using a Rapid Assessment Methodology. PLoS One. 2015. doi:10.1371/journal.pone.0132078

\section{Tables}

TABLE 1 Characteristics of subjects with influenza-like illness by laboratory test result, Bandung, Indonesia, 2009-2011

\begin{tabular}{|c|c|c|c|c|c|c|}
\hline \multirow[t]{2}{*}{ Characteristics } & \multicolumn{6}{|l|}{$\mathbf{N}(\%)$} \\
\hline & $\begin{array}{l}\text { †Negative } \\
(n=2849)\end{array}$ & $\begin{array}{l}\text { B/Yamagata } \\
(n=39)\end{array}$ & $\begin{array}{l}\text { B/Victoria } \\
(n=58)\end{array}$ & $\begin{array}{l}A(H 1 N 1) \\
(n=9)\end{array}$ & $\begin{array}{l}A(H 3 N 2) \\
(n=193)\end{array}$ & $\begin{array}{l}A(H 1 N 1) p d m 09 \\
(n=157)\end{array}$ \\
\hline Gender: Female & $1,596(56.0)$ & $19(27.5)$ & $29(50.0)$ & $2(22.2)$ & $102(52.8)$ & $76(48.4)$ \\
\hline \multicolumn{7}{|l|}{ Age group } \\
\hline $0-5$ years & $662(23.2)$ & $9(23.0)$ & $6(10.3)$ & $2(22.2)$ & 41 (21.2) & $25(15.9)$ \\
\hline $6-15$ years & $969(34.0)$ & $15(38.5)$ & $35(60.3)$ & $2(22.2)$ & 73 (37.8) & 78 (49.7) \\
\hline $16-50$ years & $1,136(39.9)$ & $14(35.9)$ & $17(29.3)$ & $5(55.6)$ & $74(38.3)$ & 49 (31.2) \\
\hline $51-65$ years & $113(4.0)$ & $1(2.6)$ & $0(0.0)$ & $0(0.0)$ & $5(2.6)$ & $5(3.2)$ \\
\hline$>65$ years & $11(0.4)$ & $0(0.0)$ & $0(0.0)$ & $0(0.0)$ & $0(0.0)$ & $0(0.0)$ \\
\hline \multicolumn{7}{|l|}{ Education } \\
\hline$\leq$ high school & $2,046(96.7)$ & $29(74.4)$ & $48(82.8)$ & $5(71.4)$ & $140(96.6)$ & $124(97.6)$ \\
\hline > high school & $69(3.3)$ & $0(0)$ & $3(5.2)$ & $2(28.6)$ & $5(3.4)$ & $3(2.4)$ \\
\hline \multicolumn{7}{|l|}{ Symptoms } \\
\hline History of fever & $2,404(84.4)$ & 38 (97.4) & $57(98.3)$ & $9(100)$ & $187(95.9)$ & 151(96.2) \\
\hline Cough & $2,526(88.7)$ & 38 (97.4) & $56(96.6)$ & $8(88.9)$ & $184(94.4)$ & $153(97.5)$ \\
\hline Sore throat & $1,984(69.6)$ & $32(82.1)$ & $42(72.4)$ & $5(55.6)$ & $125(64.1)$ & $109(69.4)$ \\
\hline Runny nose & $2,138(75.0)$ & $30(76.9)$ & $52(89.7)$ & 7 (77.8) & $156(80.0)$ & 129 (82.2) \\
\hline Headache & $1,750(61.4)$ & $31(79.5)$ & $45(77.6)$ & $5(55.6)$ & $134(68.7)$ & $110(70.1)$ \\
\hline Sneezing & $1,446(50.8)$ & $10(25.6)$ & $27(46.6)$ & $5(55.6)$ & 95 (48.7) & $71(45.2)$ \\
\hline Fatigue & $1,634(57.4)$ & $19(48.7)$ & $36(62.1)$ & $6(66.7)$ & $117(60.0)$ & $106(67.5)$ \\
\hline
\end{tabular}

† Negative result for influenza by RT-PCR assay.

TABLE 2 Estimated age-specific number of influenza cases, population size, and community health care utilization in Bandung, Indonesia, 2009-2011 


\begin{tabular}{|c|c|c|c|c|c|c|c|c|c|c|}
\hline \\
\hline \multicolumn{11}{|c|}{ Year 2009} \\
\hline $\begin{array}{l}\text { Age } \\
\text { category }\end{array}$ & $\begin{array}{l}\text { Non } \\
\text { influenza }\end{array}$ & $\begin{array}{l}\text { *Adjusted } \\
\text { numerator }\end{array}$ & $\begin{array}{l}\text { Influenza } \\
\text { A }\end{array}$ & $\begin{array}{l}\text { Adjusted } \\
\text { numerator }\end{array}$ & $\begin{array}{l}\text { Influenza } \\
\text { B }\end{array}$ & $\begin{array}{l}\text { Adjusted } \\
\text { numerator }\end{array}$ & $\begin{array}{l}\text { Total } \\
\text { ILI }\end{array}$ & $\begin{array}{l}\text { Adjusted } \\
\text { numerator }\end{array}$ & $\begin{array}{l}\text { Number of } \\
\text { population }\end{array}$ & †CHCU (\%) \\
\hline $\begin{array}{l}0-5 \\
\text { years }\end{array}$ & 132 & 440 & 18 & 60 & 11 & 37 & 161 & 537 & 8,511 & 30.0 \\
\hline $\begin{array}{l}6-15 \\
\text { years }\end{array}$ & 151 & 338 & 45 & 101 & 16 & 36 & 212 & 475 & 34,217 & 44.6 \\
\hline $\begin{array}{l}16-50 \\
\text { years }\end{array}$ & 174 & 448 & 21 & 54 & 11 & 28 & 206 & 531 & 96,766 & 38.8 \\
\hline $\begin{array}{l}51-65 \\
\text { years }\end{array}$ & 24 & 68 & 2 & 6 & 1 & 3 & 27 & 77 & 16,957 & 35.3 \\
\hline$>65$ & 4 & 6 & 0 & 0 & 0 & 0 & 4 & 6 & 6,573 & 66.7 \\
\hline Total & 485 & 1,459 & 86 & 258.6 & 39 & 117 & 610 & 1,835 & 163,024 & 33.3 \\
\hline \multicolumn{11}{|l|}{ Year 2010} \\
\hline $0-5$ & 269 & 897 & 27 & 90 & 5 & 17 & 301 & 1,003 & 8,511 & 30.0 \\
\hline $\begin{array}{l}\text { 6-15 } \\
\text { vears }\end{array}$ & 437 & 979 & 50 & 112 & 36 & 81 & 523 & 1,172 & 34,217 & 44.6 \\
\hline $\begin{array}{l}16-50 \\
\text { years }\end{array}$ & 480 & 1,236 & 41 & 106 & 17 & 44 & 538 & 1,386 & 96,766 & 38.8 \\
\hline $51-65$ & 33 & 94 & 4 & 11 & 0 & 0 & 37 & 105 & 16,957 & 35.3 \\
\hline $\begin{array}{l}>65 \\
\text { vears }\end{array}$ & 3 & 5 & 0 & 0 & 0 & 0 & 3 & 5 & 6,573 & 66.7 \\
\hline Total & 1,222 & 3,675 & 122 & 366.9 & 58 & 174 & 1,402 & 4,216 & 163,024 & 33.3 \\
\hline \multicolumn{11}{|l|}{ Year 2011} \\
\hline $\begin{array}{l}0-5 \\
\text { years }\end{array}$ & 212 & 707 & 16 & 53 & 1 & 3 & 229 & 763 & 8,511 & 30.0 \\
\hline $\begin{array}{l}6-15 \\
\text { years }\end{array}$ & 326 & 730 & 52 & 116 & 3 & 7 & 381 & 853 & 34,217 & 44.6 \\
\hline $\begin{array}{l}16-50 \\
\text { years }\end{array}$ & 418 & 1,077 & 51 & 131 & 3 & 8 & 472 & 1,216 & 96,766 & 38.8 \\
\hline $\begin{array}{l}51-65 \\
\text { years }\end{array}$ & 49 & 139 & 4 & 11 & 0 & 0 & 53 & 150 & 16,957 & 35.3 \\
\hline $\begin{array}{l}>65 \\
\text { years }\end{array}$ & 2 & 3 & 1 & 2 & 0 & 0 & 3 & 5 & 6,573 & 66.7 \\
\hline Total & 1,007 & 3,029 & 124 & 372.9 & 7 & 21 & 1,138 & 3,422 & 163,024 & 33.3 \\
\hline
\end{tabular}

Abbreviation: $\mathrm{CHCU}$, Community Health Care Utilizations

† CHCU: Community Health Care Utilization as percentage of population who sought medical care for influenza-like illness (unpublished data, Dwi Agustian et al).

* The adjusted numerator was calculated by dividing the number of cases for each age group by CHCU percentages.

TABLE 3 Estimated annual adjusted cumulative incidence of influenza-like illness by age group, Bandung District, Indonesia, 2009-2011 


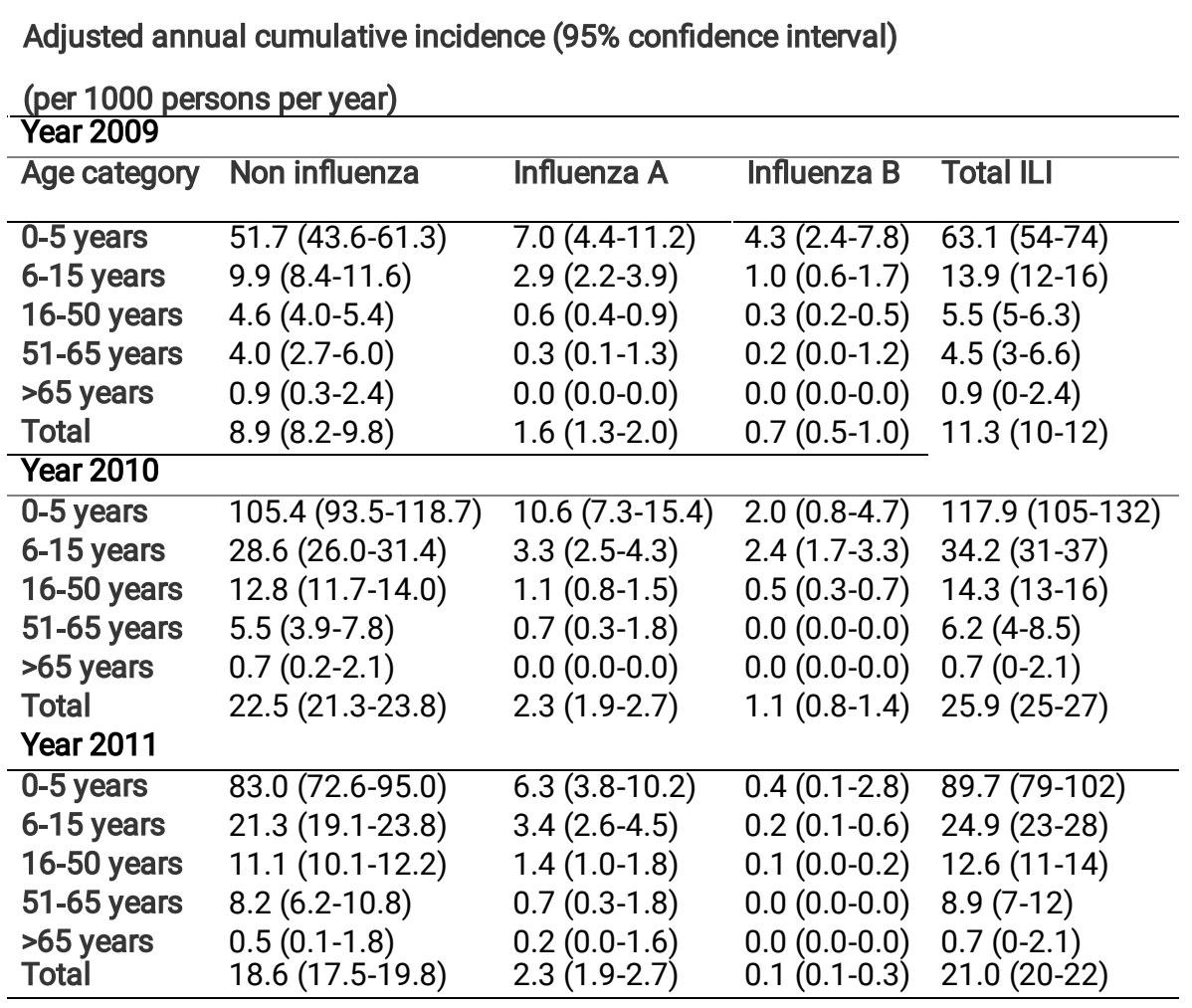

Figures 


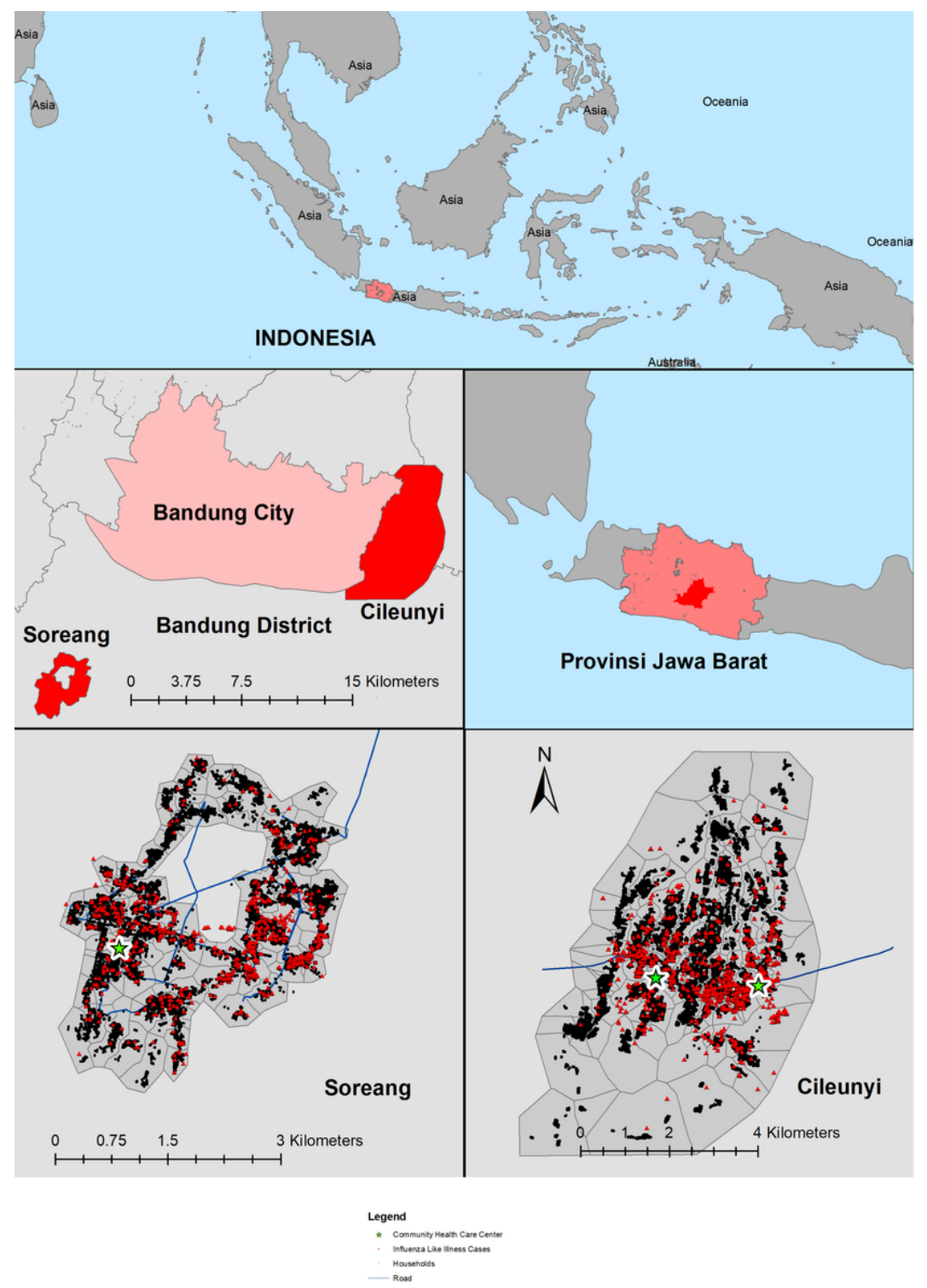

Figure 1

Study location 


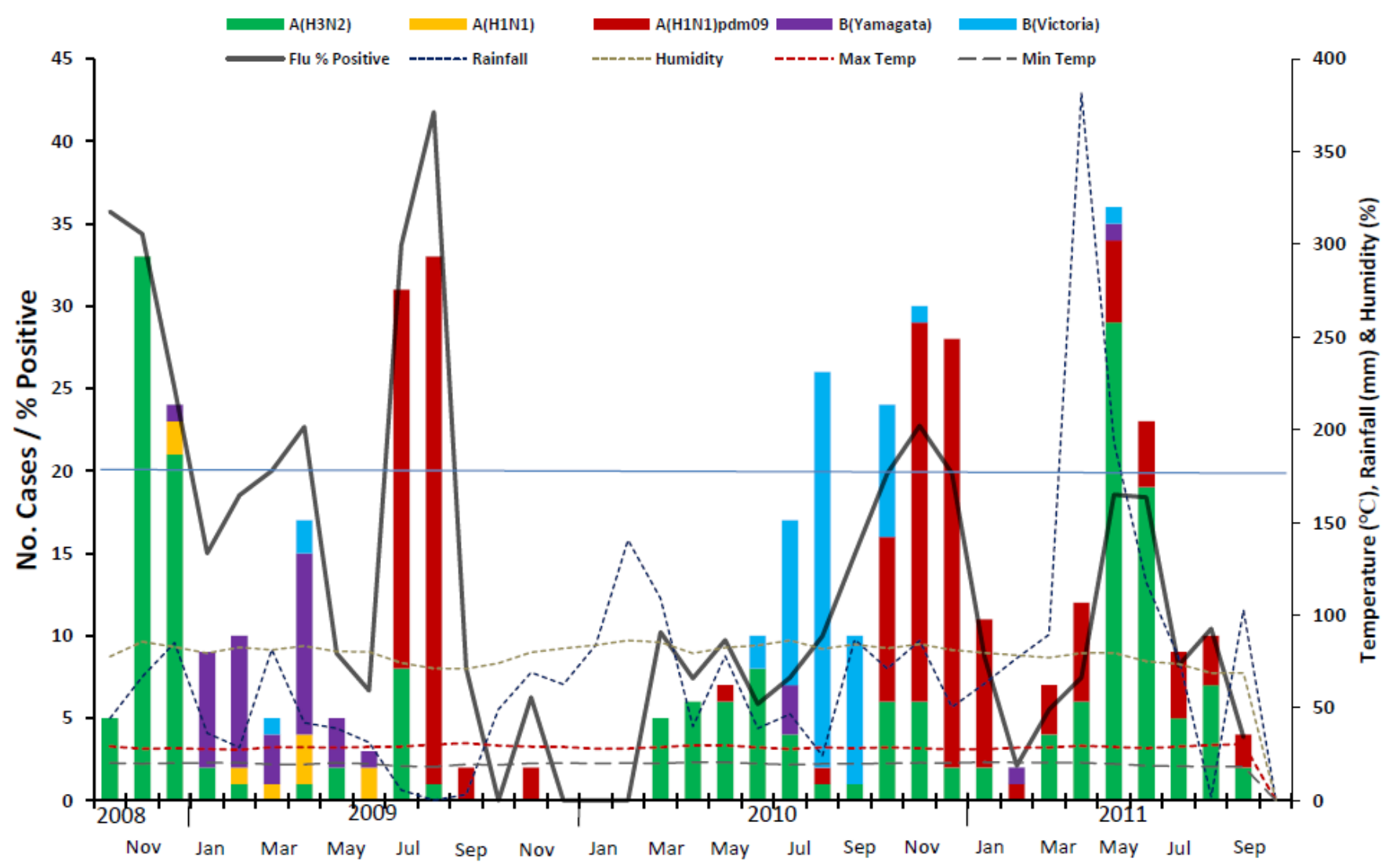

Figure 2

Seasonality of influenza viruses by type and influenza A virus subtype

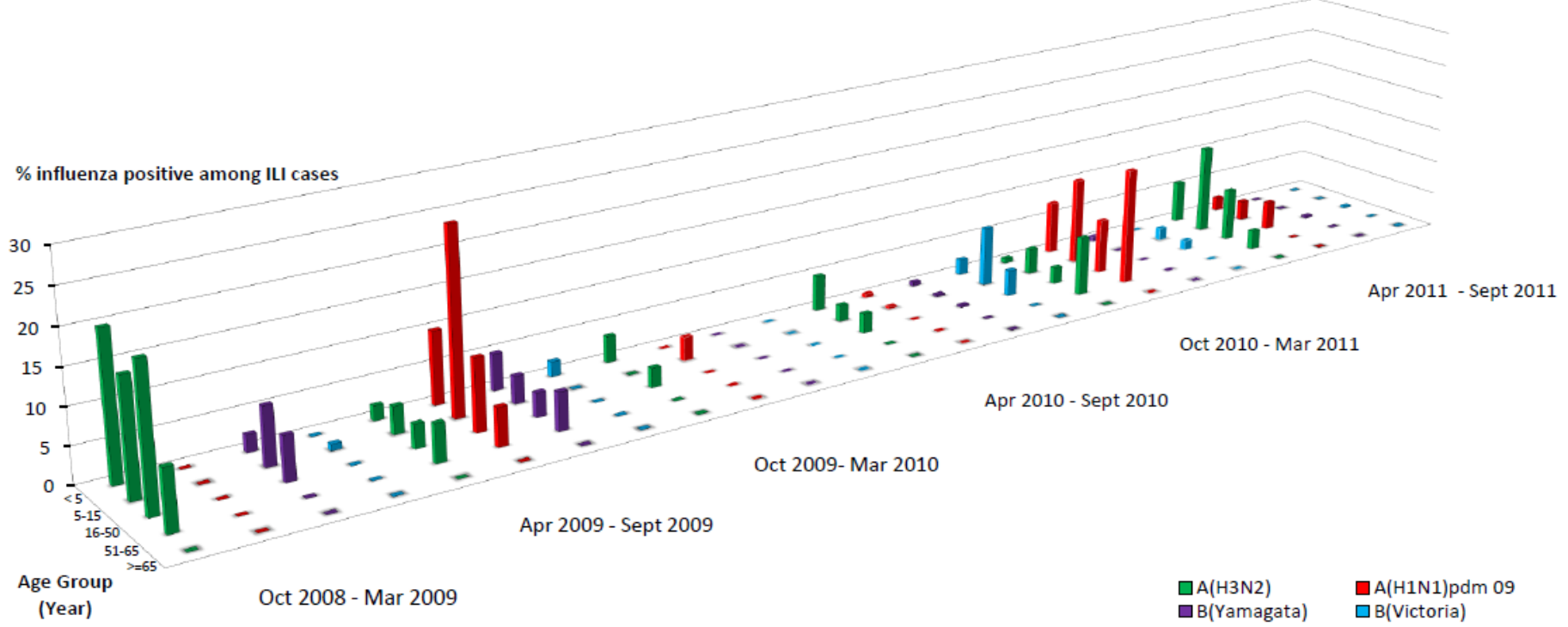

Figure 3

Age distribution of influenza positive cases by influenza virus type and time 


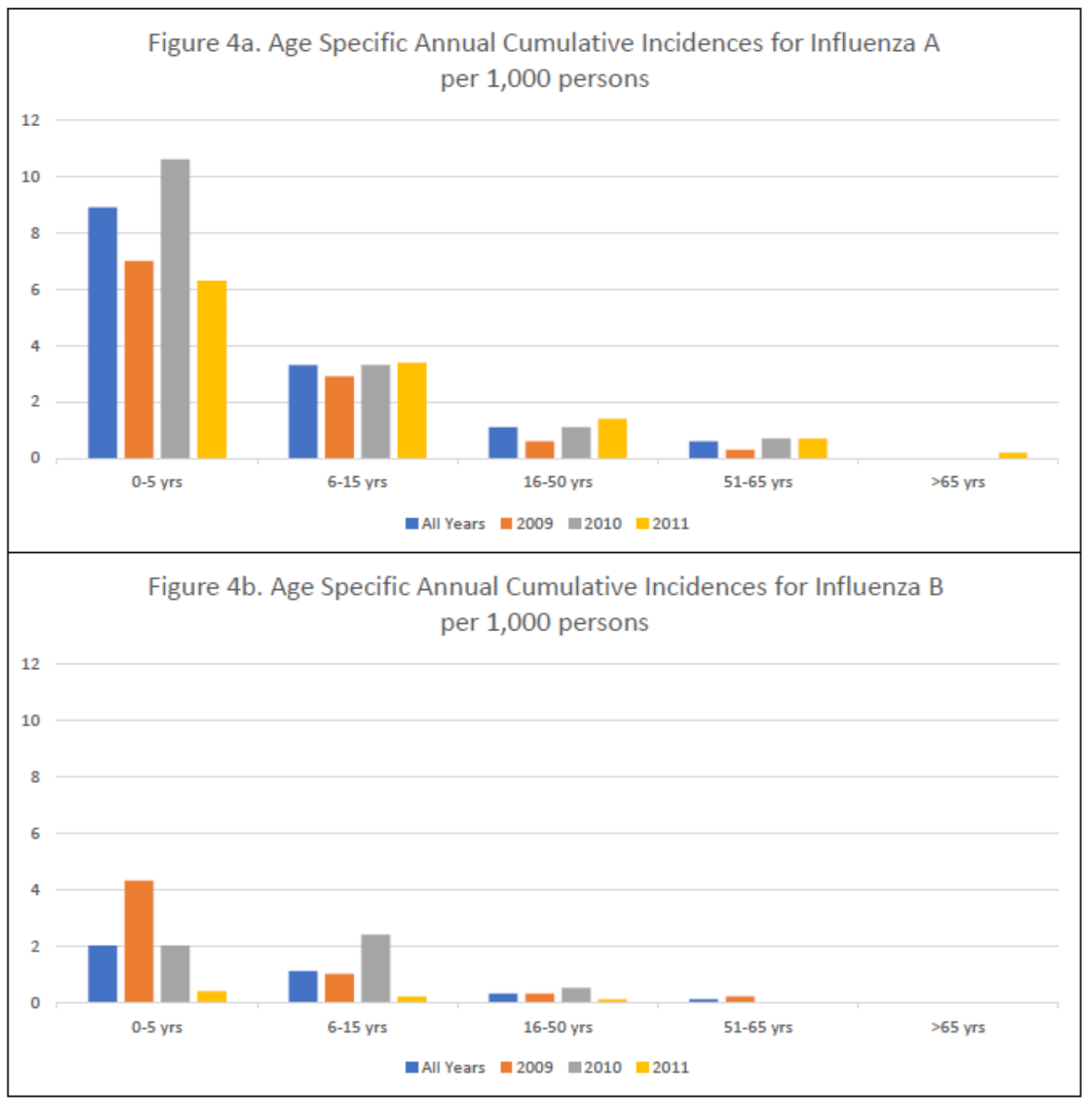

Figure 4

Age-specific estimated annual cumulative incidence for influenza A per 1000 persons

\section{Supplementary Files}

This is a list of supplementary files associated with this preprint. Click to download.

- Supplementarytable.pdf 